\title{
Aqueous interactions of zeolitic material in acidic and basic solutions
}

\author{
Ilker Polatoglu, Fehime Cakicioglu-Ozkan * \\ İzmir Institute of Technology, Chemical Engineering Department, Gulbahce Koyu, 35430-Urla-İzmir, Turkey
}

\section{A R T I C L E I N F O}

\section{Article history:}

Received 24 July 2009

Received in revised form 24 February 2010

Accepted 1 March 2010

Available online 3 March 2010

\section{Keywords:}

Natural zeolite

Aqueous interactions

Ion exchange

Adsorption

\begin{abstract}
A B S T R A C T
Aqueous interactions of natural zeolitic material in as-received and modified forms were studied. The zeolitic materials was interacted with acidic (hydrochloric acid, lactic acid, acetic acid) and basic (sodium hydroxide) solutions. Ion exchange, adsorption, complex formation, precipitation and cation hydrolysis were possible interaction mechanisms affected by the amount and cation content of zeolite and $\mathrm{pH}$. The dominant mechanisms seemed to be ion exchange and adsorption in $\mathrm{HCl}$ solution when zeolite was used in the as-received form, but dissociation of outer-sphere complexes when modified zeolite was used. In lactic acid, acetic acid as well as the basic solution, cation hydrolysis and complex formation were additional mechanism in the interactions.
\end{abstract}

(C) 2010 Elsevier Inc. All rights reserved.

\section{Introduction}

Natural zeolitic material is a crystalline, hydrated aluminosilicate of alkali and alkaline earth metals, having an infinite, open, and three dimensional structure. The primary building unit of the zeolite framework is a tetrahedron consisting of silicon or aluminum atom at the center with oxygen atoms at the corners. The main cations $\left(\mathrm{Na}^{+}, \mathrm{K}^{+}, \mathrm{Ca}^{2+}, \mathrm{Mg}^{2+}\right)$ in the channels of the framework can be substituted easily and also can compensate the positive charge deficiency of tetrahedral aluminum resulting from substitution of $\mathrm{Al}^{3+}$ by $\mathrm{Si}^{4+}[1,2]$. Additionally the hydrogen ions compensate the deficiency and therefore zeolite surface acts as a proton donor [3]. Low cost, high exchange capacity, catalytic and adsorption properties, stability as well as severity in physical properties provide its utilization for quite a number of applications such as water purification, waste treatment, food processing, cosmetics, electro coating, agricultural and pharmaceutical applications [4]. All of these aqueous systems require optimum proton concentration $\left(\left[\mathrm{H}^{+}\right]\right)$for high efficiency. The variation of the $\mathrm{pH}\left(-\log \left[\mathrm{H}^{+}\right]\right)$ in an aqueous system is controlled by many factors such as the type and particle size of the ion exchanger, concentration of the aqueous solution, type of the cation and the anion, hydrodynamics of the aqueous system and heat of solution [5].

Natural zeolitic material has mostly been studied as ion exchanger in the literature. Trgo and Peric [6] examined the removal of zinc ions from water. The removal of zinc in the acidic condition was due to the ion exchange and partly adsorption of $\mathrm{H}^{+}$ions to

\footnotetext{
* Corresponding author. Tel.: +90 232 7506644; fax: +90 2327506645 .

E-mail address: fehimeozkan@iyte.edu.tr (F. Cakicioglu-Ozkan).
}

the zeolite resulting in an increase in the $\mathrm{pH}$. In basic condition the removal of zinc ions from the solution was due to the complexion of zinc with hydroxyl ions resulting in precipitation and also the attack of $\mathrm{OH}$ ions to the zeolite structure. These behaviors caused a decrease in the pH. Ponizovsky and Tsadilas [7] showed that ion exchange was the only possible mechanism for the lead retention on clinoptilolite rich natural zeolitic material in various $\mathrm{pH}$ values. Doula and Ioannou [8] investigated the effects of electrolyte anion on $\mathrm{Cu}$ adsorption- desorption by clinoptilolite rich natural zeolitic material. Three different electrolytes $\mathrm{KCl}, \mathrm{KNO}_{3}$, and $\mathrm{K}_{2} \mathrm{SO}_{4}$ were used for desorption. It was observed that the surface was able to hold the $\mathrm{Cl}^{-}$and $\mathrm{NO}_{3}^{-}$ions via a surface complexation mechanism and this process enhanced the adsorption of $\mathrm{Cu}^{2+}$ due to the increase in surface negative charge.

The application of zeolitic material in fermentation $[9,10]$ and biological media [11,12] has been also reported. In the study of Castellar et al. [9], zeolitic material improved the production of ethanol by maintaining $\mathrm{pH}$ around 3.7 in fermentation media. This led to the consumption of all of the glucose in the fermentation so that higher ethanol concentration could be obtained in the presence of zeolite. Thus, zeolite could act as a $\mathrm{pH}$ regulator in fermentation media. This was explained with its ion exchange property. In the other study reported by Rivera et al. [13] the zeolitic material was used as an antacid for gastric disturbances. It was found that both natural zeolitic material and its $\mathrm{Na}_{2} \mathrm{CO}_{3}$ treated form raised the $\mathrm{pH}$ to the accepted range for gastric disturbance.

The aim of this study is to investigate the aqueous interactions of natural zeolitic material in acidic and basic solutions. In the study, the cation and proton/hydroxyl content of zeolite and the solution was used in order to yield information about the interactions mechanisms. 


\subsection{Theoretical background}

In aqueous interactions, natural zeolitic material tends to change the $\mathrm{pH}$ of the medium via proton transfer mechanisms. These mechanisms in the acidic or basic region can be examined by the reactions of adsorption and/or ion exchange, dissociation, cation hydrolysis and complex formation. The adsorption reaction can be associated with the exchange reaction (Reaction (1)) between $\mathrm{H}_{(\mathrm{aq})}^{+}$and surface or near-surface cations $\mathrm{M}$, such as $\mathrm{Na}^{+}$, $\mathrm{K}^{+}, \mathrm{Ca}^{2+}, \mathrm{Mg}^{2+}$. The adsorption of $\mathrm{H}^{+}$on the zeolite surface caused an increase in the solution $\mathrm{pH}$. The adsorption reaction (Reaction (2)) associated with the ion exchange results in the protonation of neutral surface as expressed with the following equations.

Ion exchange reaction : $[\mathrm{S}-\mathrm{OM}]_{\mathrm{z}}+\mathrm{H}_{(\mathrm{aq})}^{+} \leftrightarrow[\mathrm{S}-\mathrm{OH}]_{\mathrm{z}}+\mathrm{M}_{(\mathrm{aq})}$

Adsorption on neutral surface : $\underbrace{[\mathrm{S}-\mathrm{OH}]_{\mathrm{z}}}_{\text {Neutral Surface }}+\mathrm{H}_{(\mathrm{aq})}^{+} \leftrightarrow \underbrace{\left[\mathrm{S}-\mathrm{OH}_{2}^{+}\right]_{2}}_{\text {Protonated Surface }}$

where; $\mathrm{S}$ is surface central metal $(\mathrm{Si}, \mathrm{Al})$. These protonated surfaces cannot be stable in strong acidic solutions and Al and Si can be progressively removed from the zeolitic material framework [14] by the dissociation reaction as represented below.

Dissolution of framework : $\left[\mathrm{Al}-\mathrm{OH}_{2}^{+}\right]_{\mathrm{z}}+\mathrm{H}_{(\mathrm{aq})}^{+} \leftrightarrow \mathrm{Al}_{(\mathrm{aq})}^{3+}+\mathrm{H}_{2} \mathrm{O}$

$$
\left[\mathrm{Si}-\mathrm{O}^{-}\right]_{\mathrm{z}}+\mathrm{H}_{(\mathrm{aq})}^{+} \leftrightarrow \mathrm{Si}-\mathrm{OH}
$$

The cations can also be hydrolyzes and precipitate as metal oxides.

Cation hydrolysis:

$$
\begin{aligned}
{[\mathrm{S}-\mathrm{OM}]_{\mathrm{z}}+\left[\mathrm{H}+\mathrm{OH}_{(\mathrm{aq})}\right] } & \leftrightarrow\left[\mathrm{S}-\mathrm{O}^{-}\right]_{\mathrm{Z}}+\left[\mathrm{H}^{+}+\mathrm{MOH}\right]_{(\mathrm{aq})} \\
& \leftrightarrow[\mathrm{S}-\mathrm{OH}]_{\mathrm{z}}+\mathrm{MOH}
\end{aligned}
$$

Adsorption of hydroxyl ion by natural zeolite surface also causes the deprotonation of the surface as represented below.

Deprotonation of the zeolite surface :

$$
\underbrace{[\mathrm{S}-\mathrm{OH}]_{2}}_{\text {Neutral Surface }}+\mathrm{OH}_{(\mathrm{aq})}^{-} \leftrightarrow \underbrace{\left[\mathrm{S}-\mathrm{O}^{-}\right]_{2}}_{\text {Deprotonated Surface }}+\mathrm{H}_{2} \mathrm{O}
$$

As a result of these reactions (Reactions (5) and (6)), zeolite acquires an overall negative charge, due to the increasing predominance of both $\mathrm{Si}-\mathrm{O}^{-}$and $\mathrm{Al}-\mathrm{O}^{-}$groups and a decrease in the solution $\mathrm{pH}$ is observed. To maintain charge neutrality, the produced negative charge is counterbalanced by cations through complexion mechanisms; inner and outer-sphere (Reactions (7) and (8), respectively). The following reactions represent these two mechanisms for the cation in the solution.

Formation of Inner-sphere complex :

$$
[\mathrm{S}-\mathrm{OH}]_{\mathrm{z}}+\mathrm{M}_{(\mathrm{aq})}^{+} \leftrightarrow[\mathrm{S}-\mathrm{OM}]_{\mathrm{z}}+\mathrm{H}_{(\mathrm{aq})}^{+}
$$

Formation of Outer-sphere complex :

$$
\left(\mathrm{S}-\mathrm{O}^{-}\right)_{\mathrm{z}}+\mathrm{M}_{(\mathrm{aq})}^{+} \leftrightarrow\left(\mathrm{S}-\mathrm{O}^{-}\right) \ldots \mathrm{M}^{+}
$$

Actually the formation of $\left(\mathrm{S}^{-} \mathrm{O}^{-}\right)$site is required for outersphere complexion. It is rapid and reversible. On the other hand inner-sphere complexion leads to more stable surface groups due to the formation of covalent bonds. Hydrogen cations are released as products and the process causes a total decrease in the solution $\mathrm{pH}$. It is slow and irreversible $[8,15]$.

\section{Experimental}

\subsection{Materials}

In this study two sedimentary natural zeolitic materials (CL1 and CL2) from Gördes (Turkey) deposit were used. The materials were ground and dry sieved to obtain the average particle size at 30.2 and $23.6 \mu \mathrm{m}$ for CL1 and CL2 zeolites, respectively. Some of these zeolites were stored for aqueous interactions. The rest of the zeolites were treated chemically to obtain CL1 ${ }^{*}$ and $\mathrm{CL} 2{ }^{*}$. In preparation of $\mathrm{CL}_{1}{ }^{*}$ and $\mathrm{CL} 2{ }^{*}$, natural zeolitic materials CL1 and CL2 were treated with $0.5 \mathrm{M} \mathrm{Na}_{2} \mathrm{CO}_{3}$ solution (the solid to liquid ratio: $1 / 2$ ) for $1 \mathrm{~h}$. This treatment was conducted at $100{ }^{\circ} \mathrm{C}$ under reflux condition. The chemically treated CL1 was filtrated and submitted to the washing step which consisted of a 5 min agitation in deionize water. After centrifugation (Hettich micro 220R) at $9000 \mathrm{rpm}$ for $20 \mathrm{~min}$ and drying at $120^{\circ} \mathrm{C}$ for a night, one of the modified zeolitic material (CL1 ${ }^{*}$ ) was obtained. The same procedure was applied to CL2, except for the washing step, and other modified zeolite CL2 ${ }^{*}$ was obtained (Fig. 1 ). The effect of modification was compared into aqueous solution in terms of cation especially sodium and $\mathrm{H}^{+} / \mathrm{OH}^{+}$transition.

\subsection{Methods}

\subsubsection{Aqueous interactions}

Zeolitic materials CL1, CL2, CL1 ${ }^{*}$ and $\mathrm{CL} 2{ }^{*}$ were interacted with different electrolyte solutions $\left(\mathrm{HCl}, \mathrm{C}_{2} \mathrm{H}_{4} \mathrm{O}_{2}, \mathrm{C}_{3} \mathrm{H}_{6} \mathrm{O}_{3}\right.$ and $\left.\mathrm{NaOH}\right)$ at the solid/liquid ratios of $0.5,1,2,5,10(\mathrm{~g} / 100 \mathrm{ml})$. The codes for the zeolites and the concentration of the electrolyte solution used in this study were presented in Table 1 . The aqueous solution was used without adjusting $\mathrm{pH}$.

Aqueous interaction experiments were conducted at $37^{\circ} \mathrm{C}$ for acidic solutions and $27{ }^{\circ} \mathrm{C}$ for basic solutions respectively, in a water bath shaker with a rate of $200 \mathrm{rpm}$. The $\mathrm{pH}$ of the solutions was monitored by using pH meter (744 Metrohm). Solid and liquid parts were separated at equilibrium by using centrifuge (Sigma 6K15). Then the solid part was dried at room temperature and kept in plastic beaker and the liquid part was stored for analysis in an ICP-AES (Varian ICP 96). The experimental procedure was summarized as a flow diagram in Fig. 1.

\section{Zeolitic Material (as-received)}

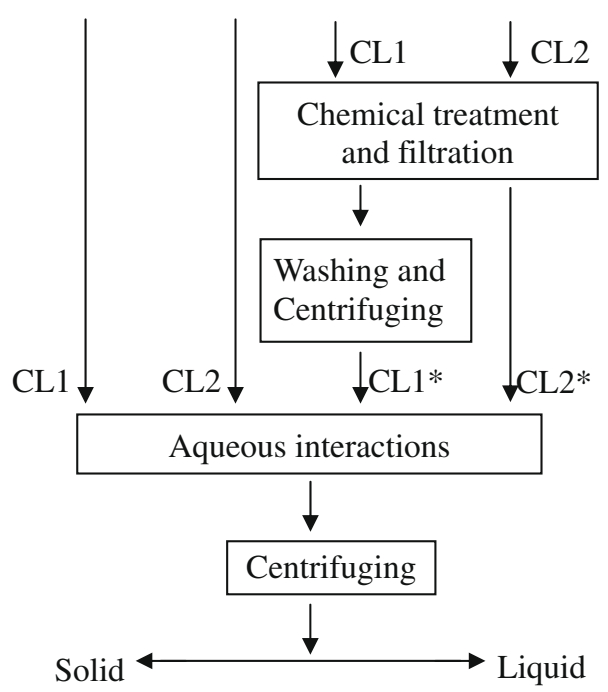

Fig. 1. Flow diagram of the experimental procedure. 
Table 1

Experimental conditions.

\begin{tabular}{|c|c|c|c|c|}
\hline Codes $^{\mathrm{b}}$ & Starting zeolite & Zeolite (w/v) & $\mathrm{pH}_{0}{ }^{\mathrm{a}}$ & $\mathrm{pH}_{\mathrm{e}}^{\mathrm{a}}$ \\
\hline Aqueous medium: (0.01 M HCl) & $C L 1(S i / A l=4.03)$ & & & \\
\hline $0.2(\mathrm{CL} 1) \mathrm{H}$ & & 0.2 & 2.00 & 2.15 \\
\hline $1(\mathrm{CL} 1) \mathrm{H}$ & & 1.0 & 2.00 & 2.29 \\
\hline $2(\mathrm{CL} 1) \mathrm{H}$ & & 2.0 & 2.00 & 2.43 \\
\hline $5(\mathrm{CL} 1) \mathrm{H}$ & & 5.0 & 2.00 & 2.84 \\
\hline $10(\mathrm{CL} 1) \mathrm{H}$ & & 10.0 & 2.00 & 3.36 \\
\hline Aqueous medium: $(0.01 \mathrm{M} \mathrm{HCl})$ & $C L 1^{*}(\mathrm{Si} / \mathrm{Al}=4.04)$ & & & \\
\hline $0.2\left(\mathrm{CL}_{*}^{*}\right) \mathrm{H}$ & & 0.2 & 2.00 & 2.26 \\
\hline $1\left(\mathrm{CL} 1_{*}^{*}\right) \mathrm{H}$ & & 1.0 & 2.00 & 3.92 \\
\hline $2\left(\mathrm{CL}_{*}^{*}\right) \mathrm{H}$ & & 2.0 & 2.00 & 8.16 \\
\hline $5\left(\mathrm{CL} 1{ }^{*}\right) \mathrm{H}$ & & 5.0 & 2.00 & 8.67 \\
\hline $10\left(\mathrm{CL}^{*}\right) \mathrm{H}$ & & 10.0 & 2.00 & 9.03 \\
\hline \multicolumn{5}{|l|}{ Aqueous medium: $\left(0.01 \mathrm{M} \mathrm{C}_{2} \mathrm{H}_{4} \mathrm{O}_{2}\right)$} \\
\hline 5 (CL2)A & & 5.0 & 2.00 & 2.33 \\
\hline \multicolumn{5}{|l|}{ Aqueous medium: $\left(\mathrm{C}_{3} \mathrm{H}_{6} \mathrm{O}_{3}\right)$} \\
\hline 5 (CL2)L4 & & 5.0 & 4.00 & 6.97 \\
\hline Aqueous medium: $\left(\mathrm{C}_{3} \mathrm{H}_{6} \mathrm{O}_{3}\right)$ & $C L 2^{*}(\mathrm{Si} / \mathrm{Al}=3.82)$ & & & \\
\hline $5\left(\mathrm{CL}^{*}\right) \mathrm{L} 2$ & & 5.0 & 2.00 & 2.85 \\
\hline $5\left(\mathrm{CL} 2{ }_{*}^{*}\right) \mathrm{L} 4$ & & 5.0 & 4.00 & 10.21 \\
\hline $5\left(\right.$ CL2 $\left.^{*}\right) \mathrm{L} 5.5$ & & 5.0 & 5.50 & 10.21 \\
\hline Aqueous medium: (0.0148 M NaOH) & $C L 2(S i / A l=3.83)$ & & & \\
\hline $1(\mathrm{CL} 2) \mathrm{S}$ & & 1.0 & 11.17 & 8.21 \\
\hline $5(\mathrm{CL} 2) \mathrm{S}$ & & 5.0 & 11.17 & 8.63 \\
\hline 10 (CL2)S & & 10.0 & 11.17 & 8.39 \\
\hline
\end{tabular}

${ }^{\mathrm{a}} \mathrm{pH}_{0}$ and $\mathrm{pH}_{\mathrm{e}}$ are the initial and equilibrium $\mathrm{pH}$ of the solution respectively.

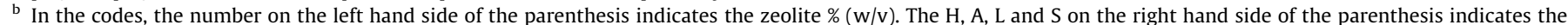
media $\mathrm{HCl}, \mathrm{C}_{2} \mathrm{H}_{4} \mathrm{O}_{2}, \mathrm{C}_{3} \mathrm{H}_{6} \mathrm{O}_{3}$ and $\mathrm{NaOH}$, respectively. The number on the right hand side of the $\mathrm{L}$ (for lactic acid) denotes the initial medium pH.

Table 2

Cation content of zeolitic materials ( $\mathrm{mmol} / \mathrm{g}$ ) and the transferred amounts.

\begin{tabular}{|c|c|c|c|c|c|c|c|}
\hline \multirow[b]{2}{*}{ Codes } & \multicolumn{5}{|c|}{ Cations (mmol/g) } & \multirow{2}{*}{$\frac{(\mathrm{mmol} / 100 \mathrm{ml})}{\left[\mathrm{H}^{+}\right]_{\mathrm{t}}}$} & \multirow{2}{*}{$\begin{array}{l}(\mathrm{meq} / 100 \mathrm{ml}) \\
{[\mathrm{M}]_{\mathrm{t}}} \\
\end{array}$} \\
\hline & $\mathrm{Na}$ & K & $\mathrm{Ca}$ & $\mathrm{Mg}$ & $\mathrm{Fe}$ & & \\
\hline Aqueous medium & \multicolumn{5}{|c|}{ Hydrochloric acid $(\mathrm{HCl})$} & & \\
\hline CL1 (initial) & 0.23 & 0.70 & 0.32 & 0.46 & 0.28 & & \\
\hline $0.2(\mathrm{CL} 1) \mathrm{H}$ & 0.09 & 0.54 & 0.06 & 0.27 & 0.27 & 0.29 & 0.24 \\
\hline $1(\mathrm{CL} 1) \mathrm{H}$ & 0.13 & 0.64 & 0.21 & 0.35 & 0.28 & 0.49 & 0.60 \\
\hline 2 (CL1)H & 0.15 & 0.66 & 0.25 & 0.38 & 0.28 & 0.63 & 0.84 \\
\hline 5 (CL1)H & 0.18 & 0.68 & 0.28 & 0.41 & 0.28 & 0.86 & 1.22 \\
\hline $10\left({ }_{*}^{(\mathrm{CL} 1) \mathrm{H}}\right.$ & 0.21 & 0.69 & 0.30 & 0.44 & 0.28 & 0.96 & 0.99 \\
\hline CL1 (initial) & 1.18 & 0.60 & 0.23 & 0.40 & 0.25 & & \\
\hline $0.2\left(\mathrm{CL}_{*}{ }^{*}\right) \mathrm{H}$ & 0.44 & 0.48 & 0.00 & 0.23 & 0.24 & 0.45 & 0.39 \\
\hline $1\left(\mathrm{CL} 1{ }_{*}^{*}\right) \mathrm{H}$ & 0.68 & 0.58 & 0.19 & 0.33 & 0.25 & 0.98 & 0.74 \\
\hline $2\left(\mathrm{CL}_{*}^{*}\right) \mathrm{H}$ & 0.81 & 0.59 & 0.22 & 0.39 & 0.25 & 1.00 & 0.84 \\
\hline $5\left(\mathrm{CL}{ }^{*}\right)_{*} \mathrm{H}$ & 0.96 & 0.60 & 0.23 & 0.39 & 0.25 & 1.00 & 1.20 \\
\hline $10(\mathrm{CL} 1) \mathrm{H}$ & 1.05 & 0.60 & 0.23 & 0.39 & 0.25 & 1.00 & 1.52 \\
\hline Aqueous medium & \multicolumn{5}{|c|}{ Acetic acid $\left(\mathrm{C}_{2} \mathrm{H}_{4} \mathrm{O}_{2}\right)$} & & \\
\hline CL2 (initial) & 0.30 & 0.77 & 0.39 & 0.46 & 0.29 & & \\
\hline $5(\mathrm{CL} 2) \mathrm{A}$ & 0.28 & 0.76 & 0.36 & 0.43 & 0.28 & 0.53 & 0.76 \\
\hline Aqueous medium & \multicolumn{5}{|c|}{ Lactic acid $\left(\mathrm{C}_{3} \mathrm{H}_{6} \mathrm{O}_{3}\right)$} & & \\
\hline $5(\mathrm{CL} 2) \mathrm{L} 4$ & 0.29 & 0.76 & 0.39 & 0.46 & 0.28 & 0.01 & 0.07 \\
\hline CL2 (initial) & 1.55 & 0.65 & 0.38 & 0.41 & 0.26 & & \\
\hline $5\left(\mathrm{CL} 2{ }_{*}^{*}\right) \mathrm{L} 2$ & 1.09 & 0.63 & 0.31 & 0.33 & 0.25 & 0.86 & 3.90 \\
\hline $5\left(\mathrm{CL} 2{ }_{*}^{*}\right) \mathrm{L} 4$ & 1.22 & 0.64 & 0.37 & 0.37 & 0.25 & 0.01 & 2.15 \\
\hline \multirow[t]{2}{*}{$5\left(\mathrm{CL} 2^{*}\right) \mathrm{L} 5.5$} & 1.24 & 0.64 & 0.37 & 0.37 & 0.25 & 0.0003 & 2.09 \\
\hline & & & & & & $\underline{\left[\mathrm{OH}^{-}\right]_{\mathrm{t}}}$ & {$[\mathrm{M}]_{\mathrm{t}}$} \\
\hline Aqueous medium & \multicolumn{5}{|c|}{ Sodium hydroxide $(\mathrm{NaOH})$} & & \\
\hline $1(\mathrm{CL} 2) \mathrm{S}$ & 0.22 & 0.75 & 0.38 & 0.33 & 0.29 & 0.15 & 0.39 \\
\hline 5 (CL2)S & 0.28 & 0.76 & 0.38 & 0.43 & 0.29 & 0.15 & 0.48 \\
\hline 10 (CL2)S & 0.29 & 0.76 & 0.39 & 0.44 & 0.29 & 0.15 & 0.50 \\
\hline
\end{tabular}

$[\mathrm{M}]_{\mathrm{t}}$ : total cation transferred to the solution (meq/100 ml).

$\left[\mathrm{H}^{+}\right]_{\mathrm{t}}$ : the proton transferred in acidic solution $(\mathrm{mmol} / 100 \mathrm{ml})$.

$\left[\mathrm{OH}^{-}\right]_{\mathrm{t}}$ : the hydroxide transferred in basic solution $(\mathrm{mmol} / 100 \mathrm{ml})$. 

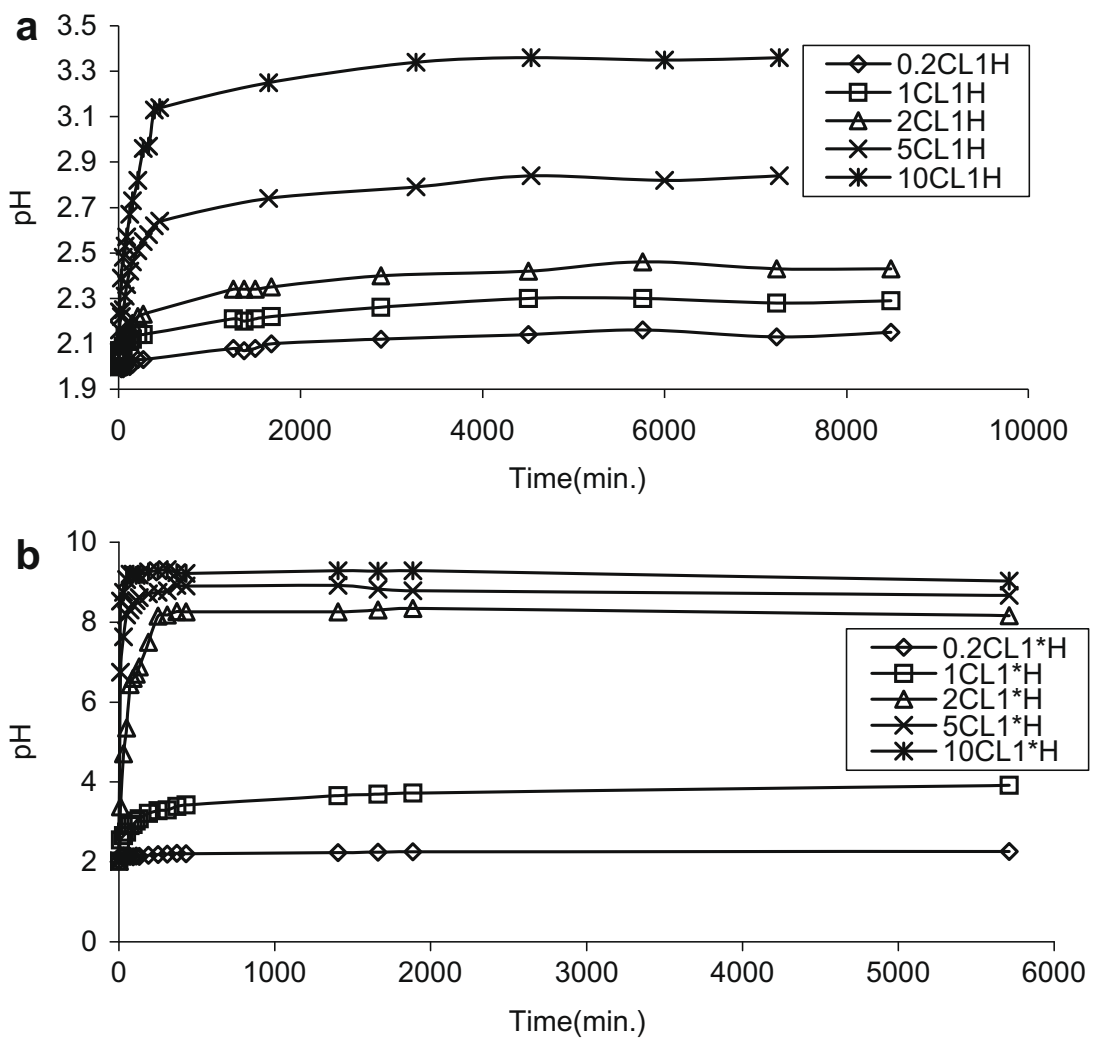

Fig. 2. Change in $\mathrm{pH}$ of $\mathrm{HCl}$ solution after the addition of (a) as-received (b) modified zeolite $\left(\mathrm{pH}_{0}=2, T=37^{\circ} \mathrm{C}\right)$.
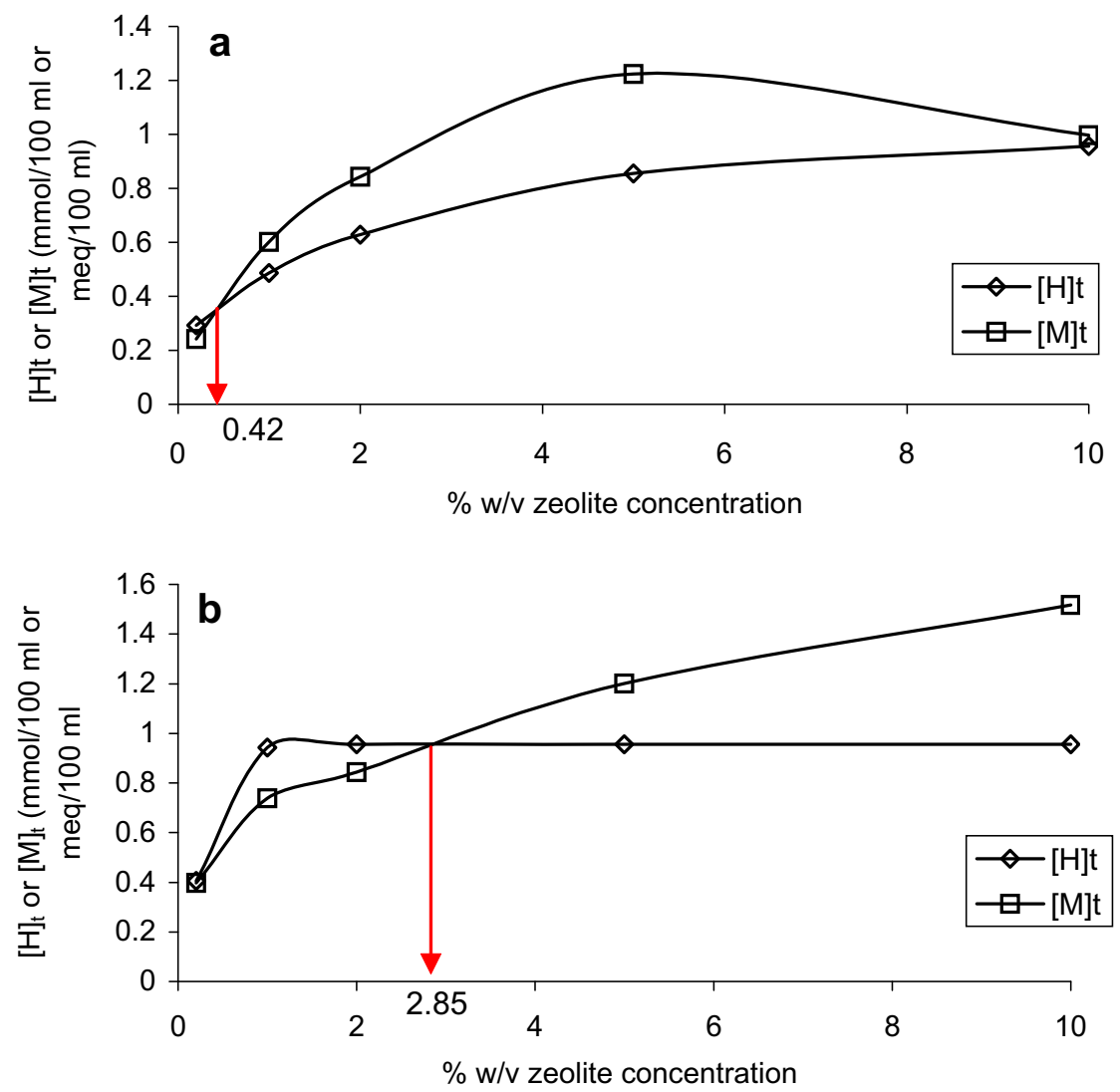

Fig. 3. Change in the cation and proton transferred amount in $\mathrm{HCl}$ solution. Zeolite form (a) as-received (b) modified. 


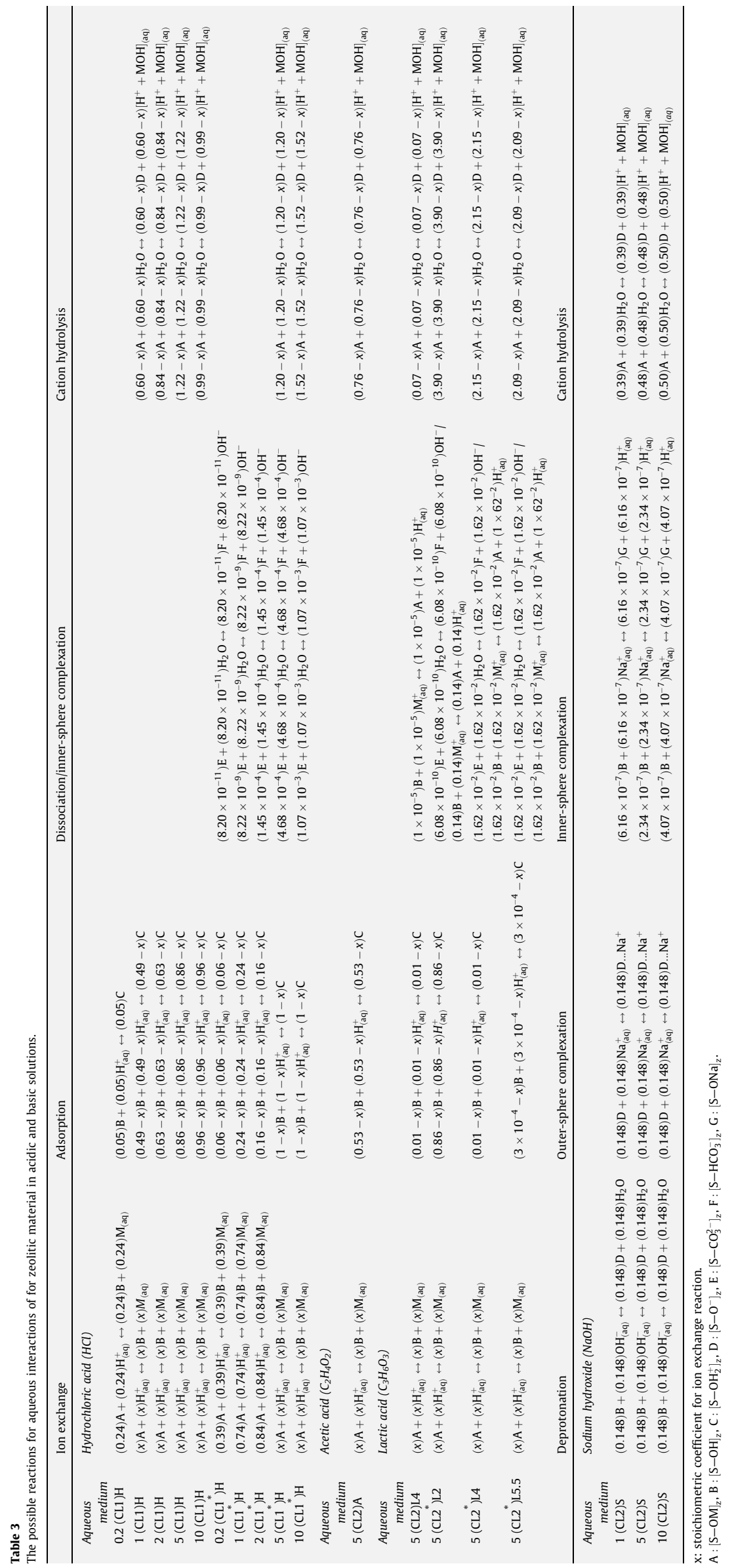




\section{Results and discussions}

\subsection{Identification and modification of zeolitic materials}

In this study, natural zeolitic materials were used in as-received (CL1 and CL2) and modified forms (CL1 ${ }^{*}$ and $\mathrm{CL} 2{ }^{*}$ ). The zeolitic minerals used in this study were heulandite-clinoptilolite rich intermediate species with $\mathrm{Si} / \mathrm{Al}$ of 4.03 and 3.83 and $\mathrm{M}^{++} / \mathrm{M}^{+}$of 0.84 and 0.79 for CL1 and CL2, respectively, according to the classification of Alietti [16]. In this classification, the ranges of $\mathrm{Si} / \mathrm{Al}$ and $\sum M^{++} / \sum M^{+}$for heulandite-clinoptilolite are 3.45-4.35 and $0.73-2.06$, respectively. $\sum M^{++}$and $\sum M^{+}$are the sum of the divalent cations and the monovalent cations, respectively.

The total exchange capacities (TEC) of CL1 and CL2 were increased from 2.49 to $3.04 \mathrm{meq} / \mathrm{g}$ and 2.77 to $3.78 \mathrm{meq} / \mathrm{g}$, respectively with chemical treatment. The TEC value represents the amount of exchangeable cations, which are considered to be $\mathrm{Na}^{+}, \mathrm{K}^{+}, \mathrm{Ca}^{2+}$ and $\mathrm{Mg}^{2+}$. CL1 has less exchangeable cations to compensate the positive charge deficiency resulting from low $\mathrm{Al}$ content. So the CL1 has higher $\mathrm{Si} / \mathrm{Al}$ ratio and lower exchange capacity when compared with the CL2. With the chemical treatment applied to CL1 and CL2, Si/Al ratio was not significantly modified.

Comparison of the initial cation content of the CL1, CL2, CL1 ${ }^{*}$ and $\mathrm{CL}_{2}{ }^{*}$ show that only the $\mathrm{Na}^{+}$content of the zeolites was increased with modification (Table 2). For CL1 and CL2, the $\mathrm{Na}^{+}$ content were increased to 0.95 and $1.25 \mathrm{mmol} / \mathrm{g}$. while the cation $\left(\mathrm{K}^{+}, \mathrm{Ca}^{++}\right.$and $\left.\mathrm{Mg}^{++}\right)$exchanged were decreased to 0.40 and $0.24 \mathrm{meq} / \mathrm{g}$ with modification. As a result the increase in sodium was higher than the decrease in the cations exchanged in zeolite. This can be explained with the formation of sphere complexes with cations on surface during the chemical treatment (modification) as stated in literature [5]. The washing step applied in the preparation of $\mathrm{CL} 2{ }^{*}$ caused to dissolve some of the complexes.

\subsection{Interactions in aqueous media}

\subsubsection{Aqueous medium: $\mathrm{HCl}$}

Fig. 2a and b display the $\mathrm{pH}$ evolution of the dilute $\mathrm{HCl}$ solution $(0.01 \mathrm{M})$. Increase in the solution $\mathrm{pH}$ was high when high amount of zeolite was used. As seen from Fig. 2b, the modified zeolites equilibrated the acidic solution at basic region $\left(\mathrm{pH}_{\mathrm{e}}>7\right)$ with a sharp increase in the solution $\mathrm{pH}$ when $2 \%, 5 \%$ and $10 \%(\mathrm{w} / \mathrm{v})$ zeolite were used. This can be explained with the dissociation of outer-sphere complexes $\left(\mathrm{S}-\mathrm{CO}_{3}^{2-}\right)$ in acid and the tendency to gain protons from acidic solution to form slightly soluble, dissociated bicarbonate ion, $\mathrm{HCO}_{3}^{-}$(Reaction (9)).

$\mathrm{S}-\mathrm{CO}_{3}^{2-}+\mathrm{H}_{2} \mathrm{O} \leftrightarrow \mathrm{S}-\mathrm{HCO}_{3}^{-}+\mathrm{OH}^{-}$

Cation content of the zeolites (Table 2) was used for the comparison of the transferred amounts. As seen from Table 2, the transferred proton $\left[\mathrm{H}^{+}\right]_{\mathrm{t}}$ increases with increasing the amount of CL1 zeolite used in $\mathrm{HCl}$ solution. The total amount of cations $\left(\mathrm{Na}^{+}, \mathrm{K}^{+}, \mathrm{Ca}^{++}, \mathrm{Mg}^{++}\right)$transferred to the solution, $[\mathrm{M}]_{\mathrm{t}}$ was not equal to the proton transferred to the zeolite $[\mathrm{H}]_{\mathrm{t}}$. The cations transferred were mostly $\mathrm{Na}^{+}$especially for the modified zeolite structure and $\mathrm{Ca}^{2+}$ ion due to its location in larger channels of the zeolite. The

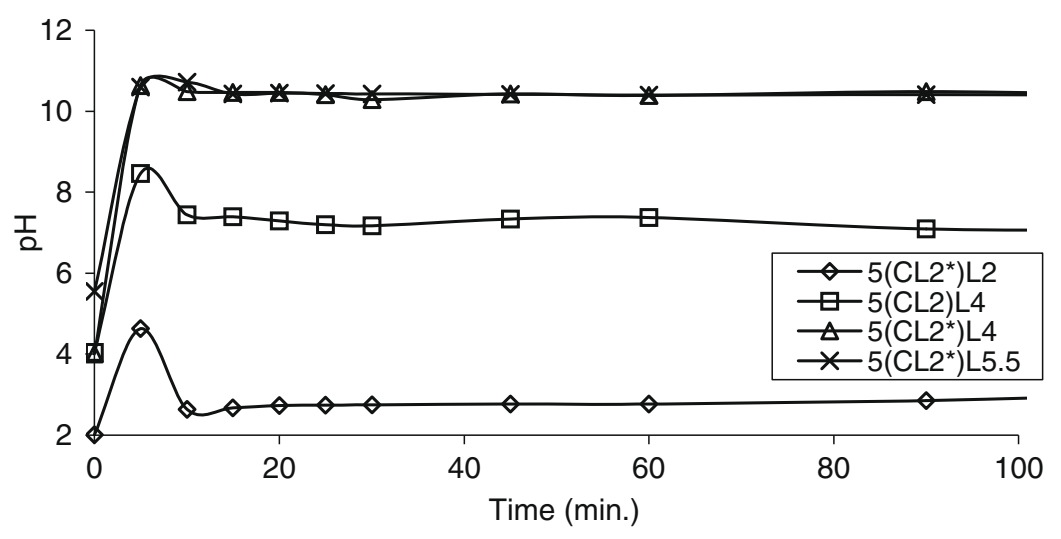

Fig. 4. Effect of initial value in $\mathrm{pH}$ evolution of lactic acid solution $\left(T=37^{\circ} \mathrm{C}\right)$.

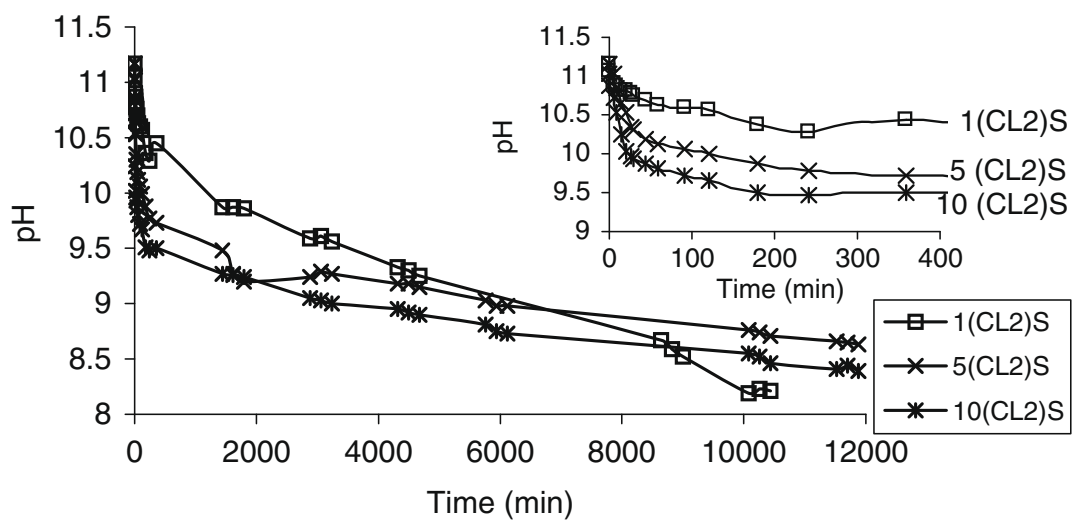

Fig. 5. Change in $\mathrm{pH}$ of sodium hydroxide solution with time $\left(\mathrm{pH}_{0}=11.17, T=27^{\circ} \mathrm{C}\right)$. 
amounts of cation transferred and proton depending on the zeolite amount were calculated and presented in Fig. 3a and b for as-received (CL1) and modified (CL1 ${ }^{*}$ ) forms of zeolite, respectively. The curves in this figure intersected at $0.42 \%$ and $2.85 \%$ zeolite amounts when as-received and modified ones were used, respectively. Up to these threshold values the proton is transferred via ion exchange and adsorption (Reactions (1) and (2)). After these threshold point the cation hydrolysis also involve the mechanism. In other words, with increasing the zeolite amount, cation concentration of the acidic solution was increased and high amount of $\mathrm{H}^{+}$ is adsorbed onto the negatively charged zeolite surface (Reaction (5)). This led to a decrease in proton concentration and thus an increase in the solution $\mathrm{pH}$ (Table 1). Dissolution of $\mathrm{Al}, \mathrm{Si}$ and Fe from zeolite lattice was not observed [17]. The possible reactions in zeolitic material-the acid and basic solution system were summarized in Table 3.

\subsubsection{Aqueous media: $\mathrm{C}_{2} \mathrm{H}_{4} \mathrm{O}_{2}$ and $\mathrm{C}_{3} \mathrm{H}_{6} \mathrm{O}_{3}$}

The time evolution of acetic acid $\left(\mathrm{C}_{2} \mathrm{H}_{4} \mathrm{O}_{2}\right)$ and lactic acid $\left(\mathrm{C}_{3} \mathrm{H}_{6} \mathrm{O}_{3}\right)$ solution $\mathrm{pH}$ in the presence of zeolite $(5 \% \mathrm{w} / \mathrm{v})$ were also studied. Zeolite increased the $\mathrm{pH}$ of the acetic acid solution from 2 to 2.33 in $480 \mathrm{~min}$ ( $8 \mathrm{~h}$ ) [17]. Ion exchange (Reaction (1)), adsorption (Reaction (2)) and cation hydrolysis (Reaction (5)) were responsible mechanisms in the acetic acid media. Since the amount of the cation transferred was higher than that of the proton transferred (Table 2).

The time evolution of lactic acid solutions $\mathrm{pH}$ is represented in Fig. 4. The initial $\mathrm{pH}\left(\mathrm{pH}_{0}\right)$ of the lactic acid solutions were 2,4 and 5.5. As seen from Fig. 4, the $\mathrm{pH}$ of the solution increased rapidly in the first minute then decrease and reached the equilibrium in a very short time $(10 \mathrm{~min})$. Ion exchange and adsorption for the rapid increase in $\mathrm{pH}$, inner sphere complex formation for the decrease in $\mathrm{pH}$ are the responsible mechanisms. Addition of the modified form of the zeolitic material $\left(\mathrm{CL}^{*}{ }^{*}\right)$ to the lactic acid solution at $\mathrm{pH}_{0}$ of 4 and 5.5 resulted in an increase in the $\mathrm{pH}_{\mathrm{e}}$ to about 10 due to the dissociation of outer-sphere complexes. In the presence of the hydroxide ion, the cation hydrolysis and the precipitations are also expected mechanisms. On the other hand, the total cation transferred $[\mathrm{M}]_{\mathrm{t}}$ is significantly higher than the proton transferred when modified zeolite was used in lactic acid solution (Table 2).

\subsubsection{Aqueous medium: $\mathrm{NaOH}$}

Fig. 5 shows the change in the $\mathrm{pH}$ of the basic solution with the addition of the zeolite. The more the zeolite was used the more the decrease in the solution $\mathrm{pH}$ was observed within initial period of times (the small figure). However this order was changed in the following time period. Therefore zeolite amount was effective on the rate of decrease of the solution $\mathrm{pH}$ while ineffective on the equilibrium $\mathrm{pH}$ (about 8.5). The decrease in the solution $\mathrm{pH}$ with the addition of zeolite can be expressed by adsorption reaction (Reaction (6)). In $\mathrm{NaOH}$ solution, the $\mathrm{OH}^{-}$ions were completely adsorbed on the zeolite structure for hydrolysis of the cation (Reaction (5)). Since the cation removed from the zeolite is higher than the transferred amount of hydroxide from solution $\left([\mathrm{M}]_{\mathrm{t}}>\left[\mathrm{OH}^{-}\right]_{\mathrm{t}}\right)$ for all zeolite amounts. This reaction leads to form inner and outer-sphere complexes (Reactions (7) and (8)) by using $\mathrm{Na}^{+}$ions initially present in the solution $\left(\left[\mathrm{Na}^{+}\right]_{\mathrm{i}}: 0.148 \mathrm{mmol} /\right.$ $100 \mathrm{ml}$ ) which causes decrease in $\mathrm{pH}$ of basic solutions.

\section{Conclusions}

The interactions of the zeolitic material in as-received and modified forms were investigated in the aqueous media of $\mathrm{HCl}, \mathrm{C}_{2} \mathrm{H}_{4} \mathrm{O}_{2}$, $\mathrm{C}_{3} \mathrm{H}_{6} \mathrm{O}_{3}$ and $\mathrm{NaOH}$. The zeolitic material used in the study increased the $\mathrm{pH}$ of the acidic solutions and decreased the $\mathrm{pH}$ of the basic solution because of its amphoteric behavior. In the time evolution of the acidic solution $\mathrm{pH}$, the modified form of the material was more effective than the as-received form. The zeolite content of the solutions was also effective on the change in $\mathrm{pH}$. Generally the proton or hydroxide ions which entered the zeolite could not equal to the cations released from the zeolite structure. Therefore ion exchange was not a unique reaction in the aqueous media. In the acidic media at low zeolite concentration, ion exchange and adsorption, which caused considerable decrease in the proton concentration of the solution to form the protonated surface, were possible mechanisms. At high zeolite concentration, cation hydrolysis and complexion were additional reactions. Dissociation was very specific reaction for modified forms of zeolitic material in acidic media. Especially in the lactic acid solution, the high amount of cation release may be result from the complex formation of lactate as sodium or calcium lactate on the surface. The decrease of the solution $\mathrm{pH}$ in $\mathrm{NaOH}$ solution was due to deprotonation, cation hydrolysis and/or inner-outer surface complexion of $\mathrm{Na}^{+}$ion on the zeolite surface.

\section{Acknowledgement}

We would like to thank Izmir Institute of Technology for the support provided by Scientific Research Project (2004 IYTE 06).

\section{References}

[1] G.V. Tsitsishvili, T.G. Andronikashvili, T.G. Kirov, L.D. Filizova, Natural Zeolites, New York, 1992.

[2] D.W. Breck, Zeolite Molecular Sieve Structure, Chemistry and Use, New York, 1974.

[3] O. Akpolat, G. Gündüz, F. Ozkan, N. Beşün, Appl. Catal. A 265 (2004) 11-22.

[4] A. Mumpton, Proc. Natl. Acad. Sci. 96 (1999) 3463-3470.

[5] R. Mirela, S.C. Stefanovic, L. Curkovic, Croat. Chem. Acta 75 (2002) 255-269.

[6] M. Trgo, J. Peric, J. Colloid Interface Sci. 260 (2003) 166-175.

[7] A.A. Ponizovsky, C.D. Tsadilas, Geoderma 115 (2003) 303-312.

[8] M.K. Doula, A. Ioannou, Microporous Mesoporous Mater. 58 (2003) 115-130.

[9] R.M. Castellar, M.R.A. Barros, M.S.J. Cabral, J.L. Iborra, J. Chem. Technol. Biotechnol. 73 (1998) 377-384

[10] B.C. Rosabal, G.R. Fuentes, Zeolites 19 (1997) 47-50.

[11] T. Farias, A.R.R. Salvador, A. Rivera, Microporous Mesoporous Mater. 61 (2003) 117-125.

[12] A. Rivera, T. Farias, A.R.R. Salvador, L.C. de Ménorval, Microporous Mesoporous Mater. 61 (2003) 249-259.

[13] A. Rivera, G.R. Fuentes, E. Altshuler, Microporous Mesoporous Mater. 24 (1998) 51-58.

[14] F. Ozkan, S. Ulku, Microporous Mesoporous Mater. 77 (2004) 47-53.

[15] M. Doula, A. Ioannou, A. Dimirkov, J. Colloid Interface Sci. 245 (2002) 237-250.

[16] A. Alietti, Am. Mineral. 57 (1972) 1448-1462.

[17] İ. Polatoglu, Chemical Behavior of Clinoptilolite Rich Natural Zeolite in Aqueous Medium, MS Thesis, İzmir Institute of Technology, 2005. 